\title{
Correction to: Effects of workload, work complexity, and repeated alerts on alert fatigue in a clinical decision support system
}

Jessica S. Ancker ${ }^{1,2^{*}}$, Alison Edwards ${ }^{1,2}$, Sarah Nosal ${ }^{3,4}$, Diane Hauser ${ }^{3}$, Elizabeth Mauer ${ }^{1}$, Rainu Kaushal ${ }^{1,2}$ and with the HITEC Investigators

\section{Correction to: BMC Medical Informatics and Decision} Making (2017) 17:36

https://doi.org/10.1186/s12911-017-0430-8

Following publication of the original article [1], the authors reported that the article erroneously stated that Dr. Ancker was affiliated with the Tehran University of Medical Sciences. Dr. Ancker is not affiliated with that institution.

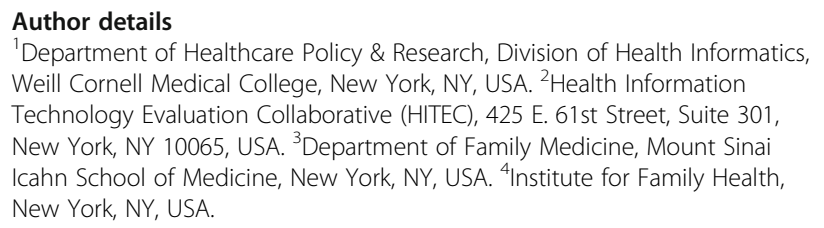

Published online: 18 November 2019

\section{Reference}

1. Ancker, et al. BMC Medical Informatics and Decision Making. 2017;17:36. https://doi.org/10.1186/s12911-017-0430-8.

\footnotetext{
The original article can be found online at https://doi.org/10.1186/s12911017-0430-8

* Correspondence: jsa7002@med.cornell.edu

'Department of Healthcare Policy \& Research, Division of Health Informatics, Weill Cornell Medical College, New York, NY, USA

${ }^{2}$ Health Information Technology Evaluation Collaborative (HITEC), 425 E. 61 st

Street, Suite 301, New York, NY 10065, USA

Full list of author information is available at the end of the article
}

(c) The Author(s). 2019 Open Access This article is distributed under the terms of the Creative Commons Attribution 4.0 International License (http://creativecommons.org/licenses/by/4.0/), which permits unrestricted use, distribution, and reproduction in any medium, provided you give appropriate credit to the original author(s) and the source, provide a link to the Creative Commons license, and indicate if changes were made. The Creative Commons Public Domain Dedication waiver (http://creativecommons.org/publicdomain/zero/1.0/) applies to the data made available in this article, unless otherwise stated. 